\title{
Morphology and anatomy of anomalous cladodes in Sciadopitys verticillata Siebold \& Zucc. (Sciadopityaceae)
}

\author{
V. M. Dörken · T. Stützel
}

\begin{abstract}
The needles of Sciadopitys verticillata Siebold \& Zucc. (Sciadopityaceae) are inserted in the axils of the reduced scaly leaves and are thus generally regarded as cladodes. The evolutionary pathway leading to these cladodes remained, however, dubious and conflicting interpretations are given. Intermediate morphological structures are known basically from one single paper (Carrière 1868), giving only line drawings of the morphology without any further anatomical details. Attempts to produce such intermediate cladodes in experiments failed, but amongst thousands of checked individuals by chance one was found displaying such intermediate or malformed cladodes. These were analyzed morphologically and anatomically in detail. The results gave new insights into the evolution of these cladodes and might raise new questions about the monophyletic origin of the gymnosperm leaf.
\end{abstract}

Keywords Gymnosperms - Sciadopitys - Cladode . Morphology $\cdot$ Anatomy

\section{Introduction}

The umbrella-like arranged needles of Sciadopitys verticillata are inserted in the axils of small brown, scaly bracts. Unlike "typical" needle leaves of other conifers they have thus to be regarded as cladodes. These cladodes are the only assimilating organs in the mature plants of

Communicated by U. Luettge.

V. M. Dörken (西) · T. Stützel

Institute for Biodiversity and Evolution of Plants,

Ruhr-University Bochum, Bochum, Germany

e-mail: veit.doerken@rub.de
Sciadopitys. The tip of the needles indicates that two leaves are involved in their formation and they are hence frequently termed as "double needles". Their morphological interpretation is still controversial, although it was the subject of many morphological and genetic studies (e.g., Carrière 1868; Dickson 1866; Engelmann 1868; Mohl 1871a, b; Strasburger 1872; Schneider 1913; Troll 1937; Roth 1962; Tetzlaf 2004; Hille 2002, 2008). There are basically two different interpretations for the morphology and the evolution of these "double needles". The first regards them as flattened short shoots with two strongly reduced leaves at the tip. This means that nearly the entire cladode would be formed by the shoot tissue. The second hypothesis regards the cladode as being formed more or less exclusively by two leaves. The shoot apex would degenerate early and its rudiment could be at the base of the cladode as well as near its distal end. In this case the short shoot would be strongly reduced and its apical meristem is absorbed by the growing leaf primordial and most part of the double needle would consist of the leaf parenchyma.

A better understanding of the morphology, anatomy and the development of the "double needles", which we call now cladodes, might help to understand the evolution of this monotypic taxon. The problem is that intermediates between cladodes and normal leaves are hardly known. In 1868 Carrière described an individual with intermediates between cladodes and true leafy shoots (Fig. 1). This is the only record so far. After having checked several hundred individuals in nurseries, collections and gardens we found an 8-year-old individual showing such exceptional branches. They represented different developmental stages, but the initial stages were not available. As a further abnormality our plant showed well-developed green leaves instead of the scale like sterile bracts in some parts on the 


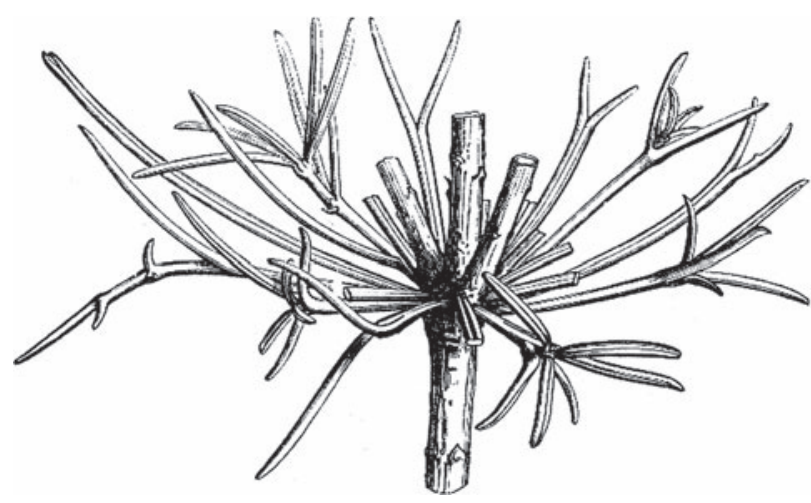

Fig. 1 Drawing of Sciadopitys verticillata by Carriere (1868); up to now this was the only documented record of intermediates between cladodes and leafy short shoots

long shoots. These leaves can be regarded as an atavism, giving information about the anatomy of a presumed ancestral normal leaf which is not formed in typical mature individuals.

In addition, we studied the anatomy of the cotyledons (Fig. 3) and the two subsequent normal leaves, the primary leaves (Fig. 4) as well as the reduced scale-like bracts (Fig. 5) and the cladodes (Fig. 8) of normal Sciadopitys plants. This allowed a broad morphological and anatomical comparison, which contributes towards a good understanding of the cladodes of Sciadopitys.

\section{Materials and methods}

Unusual cladode formation and intermediates between cladodes and "leafy" short shoots were found only on a single individual of $S$. verticillata bought in a garden centre in autumn 2008. Seedlings where produced in the Botanic Garden Bochum in a temperate glass house from seeds obtained from the Botanic Garden Marburg, and normal shoots with cladodes were obtained also from the Botanic Garden Bochum.

For the individual with malformed cladodes and short shoots, the position within the branching system and the morphology were documented by line drawings and photos taken with a Nikon Coolpix 995. Then they were removed, photographed again and then fixed in FAA, later stored in $70 \%$ alcohol. Hand sections were made with a razor blade. For serial sections classical paraffin technique and subsequent safranin/astrablue staining were used (Gerlach 1984). In the field, photos were made with a Canon PowerShot IS 2.

Microphotographs were made using a dissection microscope Zeiss SV 11 and a light microscope Zeiss Axioplan. Both microscopes were supplied with an Olympus ColourView II ${ }^{\circledR}$ camera. We used the analySIS ${ }^{\circledR}$ software version 3.2build776, for recording and multiple image alignment.

The side the individual leaves turned towards the axis is called the adaxial side. The side the cladode exposed to the sun is termed as the upper side. "Abaxial side" and "lower side" are used, respectively. We avoided using "adaxial" and "abaxial" for the cladodes as it is frequently done. Adaxial and abaxial should be used only when referring to the axis on which the individual leaf is inserted.

\section{Results}

Morphology of different malformed short shoots

Different types of malformed short shoots were found. Short shoots bearing a vegetative bud on the lower side of the cladode are most similar to the normal cladodes. The bud was always found on the lower and never on the upper side (Fig. 2). Other malformed cladodes bore dispersed small undeveloped leaves and terminated in a rudimentary apex (Fig. 7). The most complex short shoots showed in
Fig. 2 Buds on the lower side of cladodes in Sciadopitys verticillata a anomalous cladode showing a rudimentary bud on the lower side. b Anomalous cladode with full developed vegetative bud on the lower side
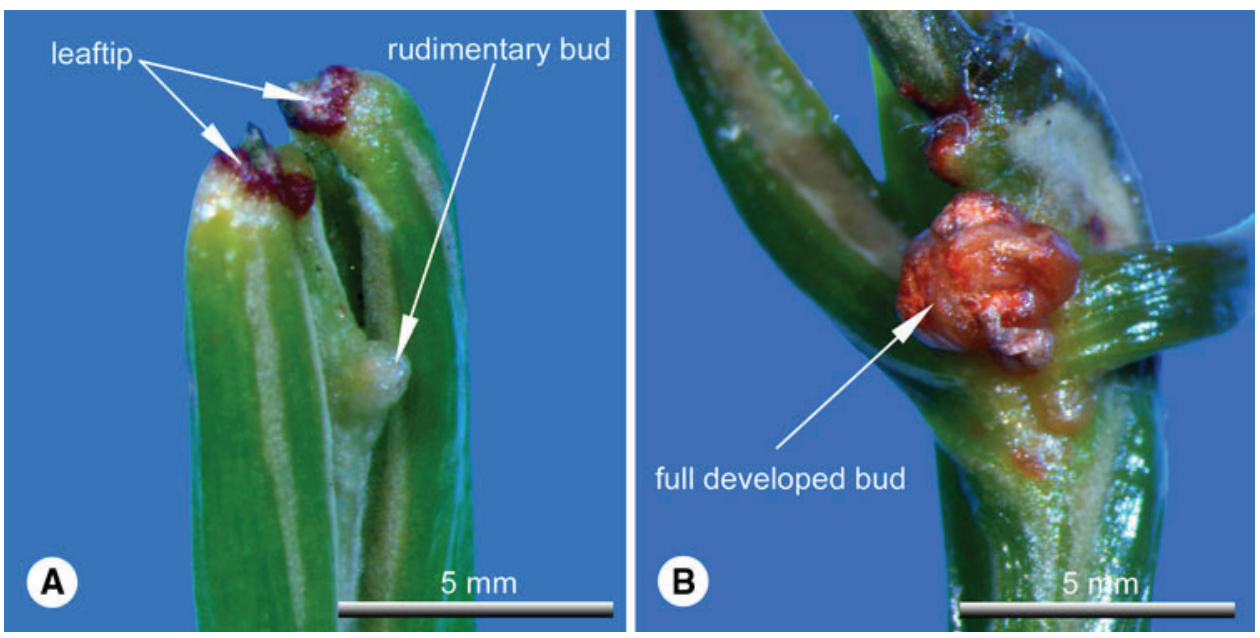
Fig. 3 Morphology and anatomy of cotyledons of Sciadopitys verticillata. a Seedling with two cotyledons. b Cross section of a cotyledon; xylem $(X)$ arranged to the adaxial and phloem $(P)$ to the abaxial side; mesophyll is monomorphous; resin ducts are predominantly arranged on the abaxial side. c The vascular bundle is surrounded by a vascular bundle sheet $(V B S)$. d Stomata $(S)$ are on the abaxial side; a cuticula $(C)$ covers the epidermis $(E)$
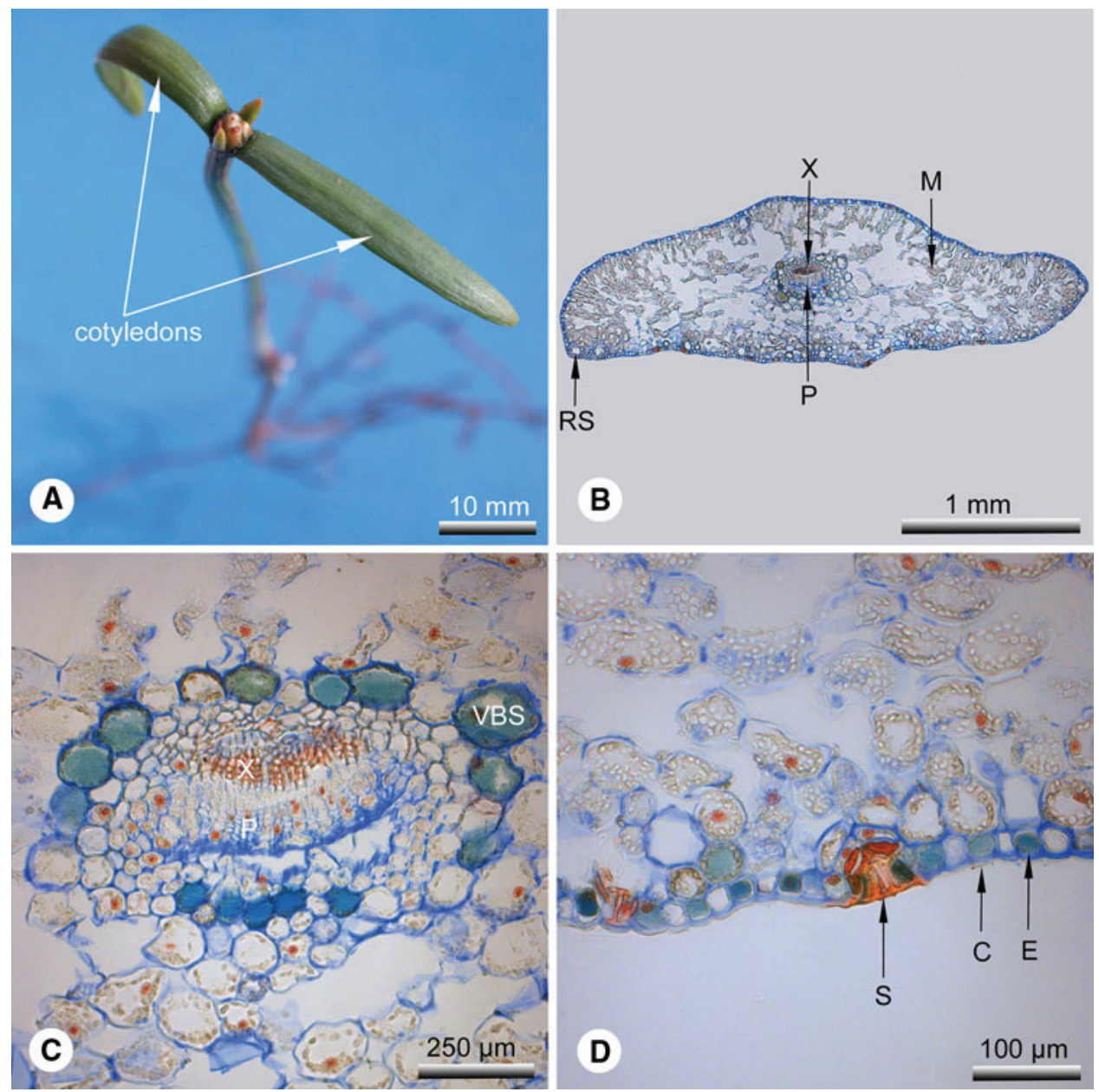

the basal part, a more or less cladode-like morphology followed by some more or less dispersally positioned leaves and in the distal part cataphylls with normal axillary cladodes. The latter shoots terminated in a well-developed apical bud with some cataphylls (Fig. 11). Within the branching system the more developed anomalous short shoots were more basal close to the lateral long shoots of the same year and the most reduced ones more distal close to the normal cladodes of the terminal long shoots (Fig. 13).

\section{Leaf and cladode anatomy}

We studied several different types of leaves or leaf-like structures: the cotyledons (Fig. 3), the subsequent primary leaves (Fig. 4), scale-like long-shoot leaves (Fig. 5), anomalous leafy long-shoot leaves (Fig. 6), anomalous short-shoot leaves (Fig. 7) and normal cladodes (Fig. 8). In anomalous cladodes the parts appearing equivalent to the individual leaves and the more basal part presumably representing the cladode part were studied separately.

\section{Cotyledons}

Seedlings of $S$. verticillata generally develop two cotyledons (Fig. 3a). Cross sections show an epidermis with a prominent cuticle, a hypodermis is wanting. The leaf is more or less aequifacial, the entire mesophyll shows large intercellular spaces (Fig. 3b). There are more than ten resin ducts that are arranged close to the hypodermal layer, predominantly on the abaxial side. Cotyledons are hypostomatic (Fig. 3d). The vascular bundle has a prominent bundle sheet and the xylem is directed to the adaxial and phloem to the abaxial side (Fig. 3c).

\section{Primary leaves}

Seedlings of $S$. verticillata generally have two primary leaves, which seem to be inserted at slightly different levels, the first one being frequently slightly larger than the second (Fig. 4a). The anatomy of the primary leaves shows a typical needle leaf structure (Fig. 4b). The epidermis has a prominent cuticula. A hypodermal layer with strongly 
Fig. 4 Morphology and anatomy of primary leaves of Sciadopitys verticillata. a Seedling with two primary leaves. b Cross section of a primary leaf; xylem $(X)$ to the adaxial and phloem $(P)$ to the abaxial side; mesophyll differentiated in palisade $(P P)$ and spongy parenchyma $(S P)$; resin ducts $(R S)$ are in lateral parts and in the middle of the abaxial side. c The vascular bundle is surrounded by a vascular bundle sheet $(V B S)$ d Stomata $(S)$ on the abaxial side; the hypodermis $(H)$ has thickened cells; a cuticula $(C)$ covers the epidermis $(E)$
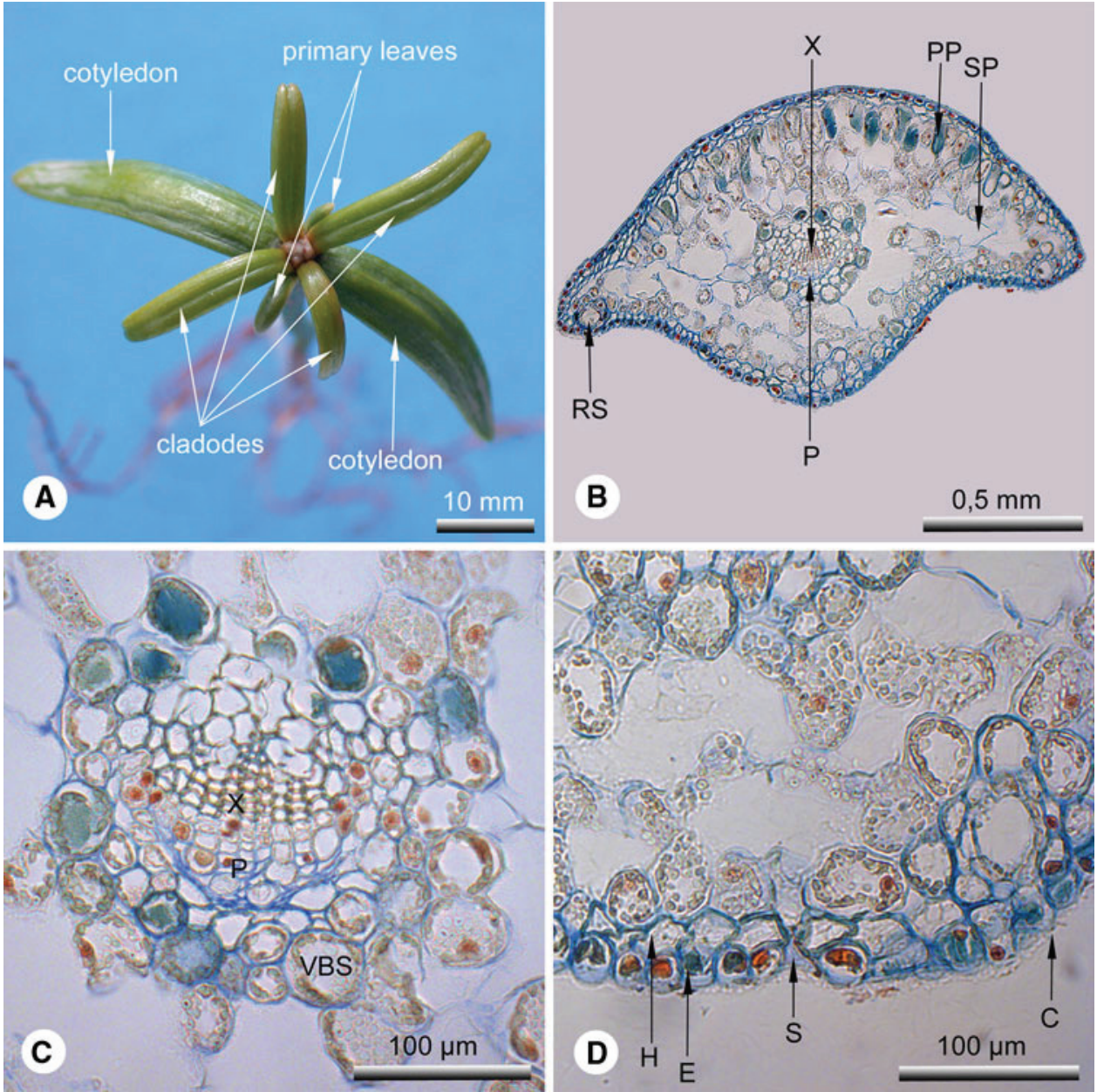

thickened cell walls is present. The mesophyll is differentiated into an adaxial palisade and an abaxial spongy parenchyma. There are two resin ducts, one on either side of the vascular bundle. The bundle has a well-developed bundle sheet. The xylem points to the adaxial and the phloem to the abaxial side (Fig. 4c). Stomata are restricted to the abaxial side (Fig. 4d).

\section{Scale-like long-shoot leaves}

The long-shoot leaves of typical individuals of Sciadopitys are rudimentary, brown and without chlorophyll (Fig. 5). They have a single resin duct. A vascular bundle is usually lacking. If there is a rudimentary bundle, it is not connected to the stem bundle.

\section{Leafy, green long-shoot leaves}

In some parts of the plant, our individual showed about $6 \mathrm{~cm}$ long leafy green long-shoot leaves (Fig. 6a). Cross sections of such a long-shoot leaf (Fig 6b-d) show an anatomy similar to the primary leaves (Fig. 4). The leaf is hypostomatic, the mesophyll not differentiated into palisade and spongy parenchyma. There are about ten resin ducts, out of which only two of them are close to the abaxial side.

\section{Leaves of anomalous short shoots}

Some anomalously shaped cladodes are connate only in half of their length and terminate in a shoot axis with some lateral leaves in spiral arrangement and a bud (Fig. 7a). In a transverse section these leaves are triangular and aequifacial. The mesophyll is uniformly developed. A single resin duct occurs on the abaxial side, below the vascular bundle (Fig. 7b). The xylem is situated on the adaxial and phloem on the abaxial side of the leaf (Fig. 7c). Stomata are arranged in lines between the papillae on all three sides of the leaf (Fig. 7d). The leaf is thus aequifacial and amphistomatic. 
Fig. 5 Morphology and anatomy of typical rudimentary, scaly long-shoot leaves. a-c Cross sections from distal to proximal parts of the leaves (a taken from an other sample than $\mathbf{b}$ and $\mathbf{c}$ ); typical long shoot leaves have only one median resin duct; a vascular bundle is lacking; mesophyll not differentiated in spongy and palisade parenchyma. d Typical long shoot leaves are scaly and without chlorophyll
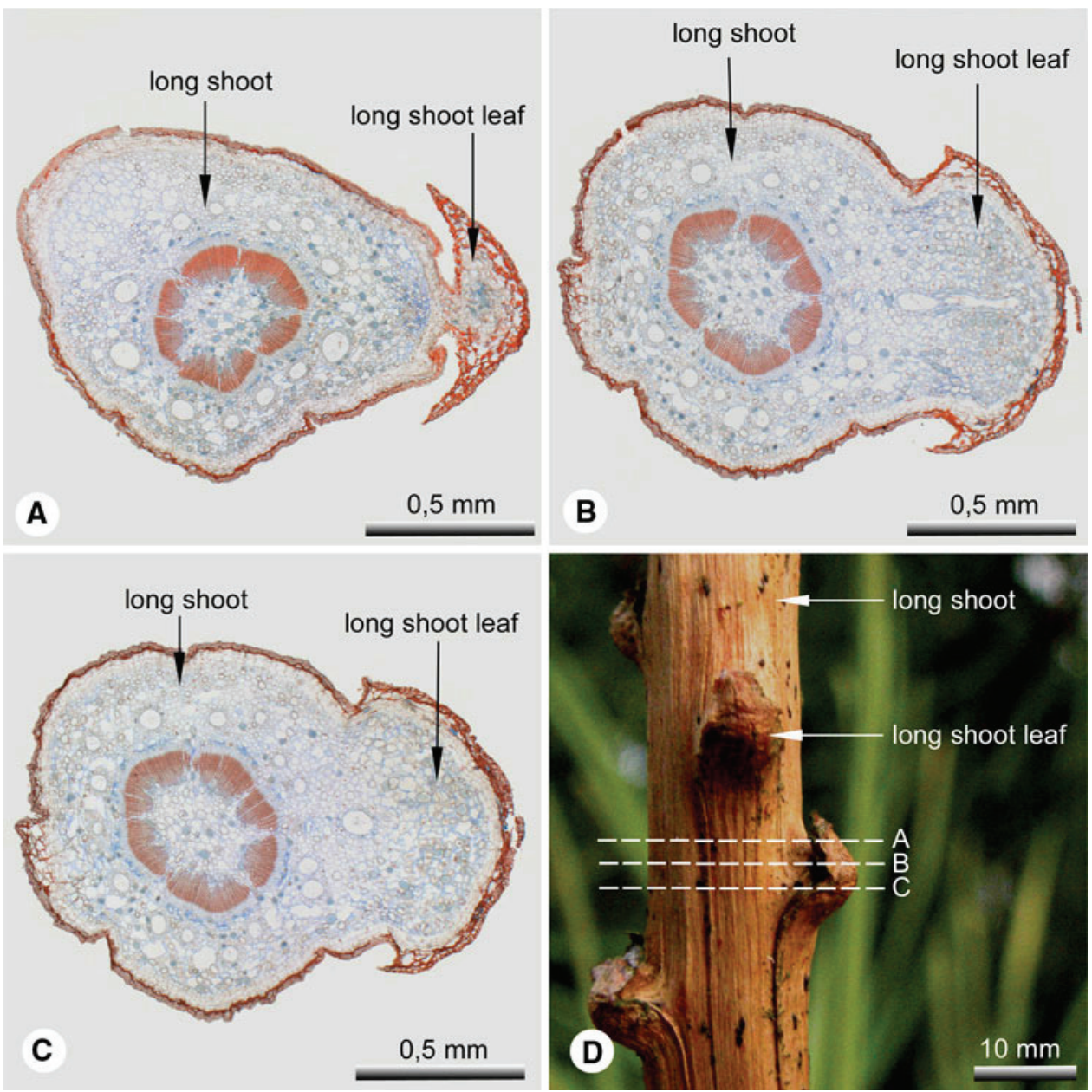

\section{Typical cladodes}

Typical cladodes of S.verticillata are about 10-15 cm long (Fig. 8a). They are inserted in the axils of scaly bracts on the long shoots. A longitudinal furrow is developed on both sides of the cladode, but is more prominent on the lower side (Fig. 8b). In this furrow the stomata are concentrated in longitudinal rows between the papillae. A well-developed cuticula covers the epidermis. The hypodermal cells are strongly thickened (Fig. 8d). The mesophyll is differentiated into palisade and spongy parenchyma. The palisade parenchyma is found on the upper, and the spongy parenchyma on the lower side of the cladode. There are four resin ducts, two occur on the upper and two on the lower side. The cells of the spongy parenchyma are more or less isodiametric. The intercellular spaces in the spongy parenchyma are large. Each of the two vascular bundles is surrounded by its own bundle sheet (Fig. 8c). The xylem of both bundles is directed to the furrow of the lower side (Fig. 8b). At the base of the cladode, these two bundles merge into a single more or less concentrical bundle before entering the main axis. Rudiments or other remains of a short shoot axis are not to be seen.

\section{Malformed cladodes with free ends}

Some cladodes of our 8-year-old individual did not show the tip of a typical cladode but terminated into two long free ends (Fig. 9a). A structure that could be interpreted as a shoot apex could not be seen between these free ends or in another position. The basal part (Fig. 9b) is similar to a normal cladode in morphology as well as in anatomy. In the free ends, the xylem of both the parts face each other like in opposite leaves. There are 11 resin ducts, which occur mostly on the upper side. No remainder of a shoot axis could be found in these cladodes.

\section{Cladodes with three vascular bundles}

Some cladodes showed three leaf tips (Fig. 10a). Cross sections of these cladodes showed three vascular bundles (Fig. 10b). The xylem of all three is oriented towards the 
Fig. 6 Abnormalous long-shoot leaves. a Long shoot with "leafy" leaves. b Cross section of a long shoot leaf; xylem $(X)$ on the adaxial and phloem $(P)$ on the abaxial side; mesophyll is monomorphous; most resin ducts (RS) on the adaxial side. c The vascular bundle is surrounded by a vascular bundle sheet $(V B S)$. d Stomata $(S)$ are on the abaxial side; a hypodermis is well developed $(H)$; the epidermis $(E)$ is covered with a cuticula $(C)$
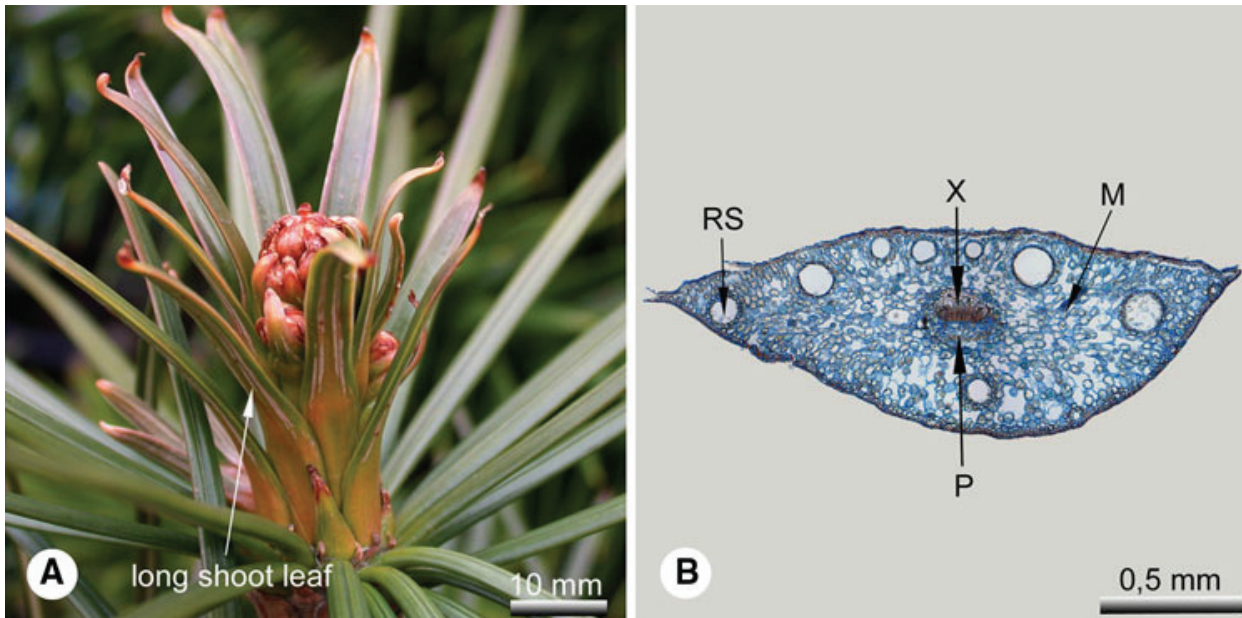

long shoot lea

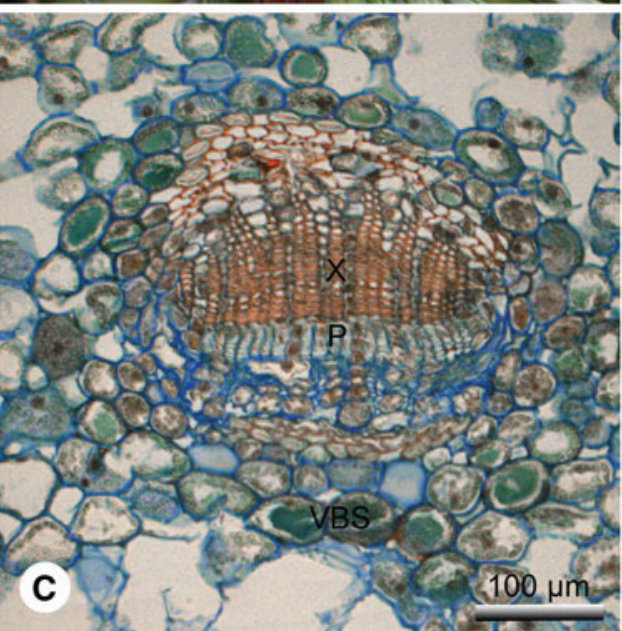

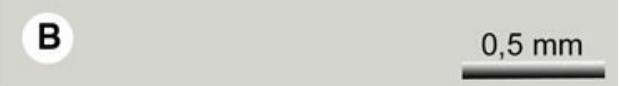

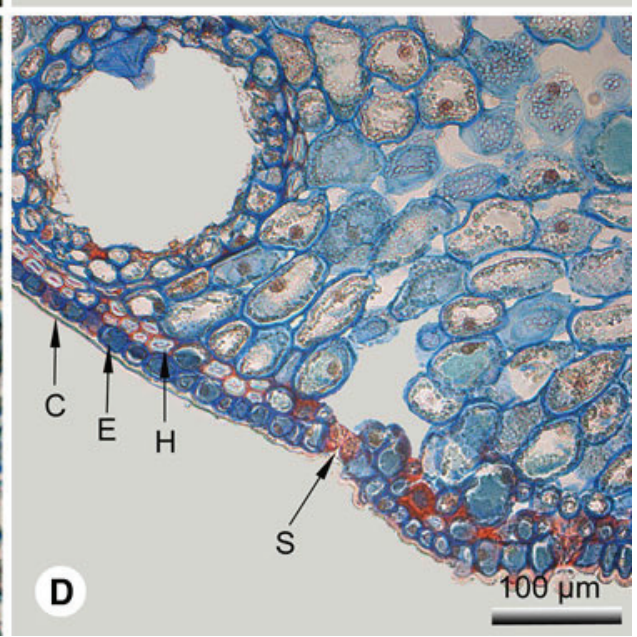

ventral furrow. There were four resin ducts, three were positioned near the upper and one to the lower side. Other features (Fig. 10c, d) resemble those of the typical cladodes. No remainder of a shoot axis could be detected (Fig 10).

\section{Short shoot with prominent shoot axis}

Some malformed cladodes of our individual showed a prominent shoot axis. One malformed cladode (short shoot) was 2 years old and positioned basal in the annual growth unit. The basal part of this short shoot or malformed cladode showed several normal leaves. The most basal two were inserted nearly opposed, with the part basal to the insertion appearing morphologically similar to a normal cladode. The following four leaves where arranged spirally and inserted close together at the end of a relatively long internode. The shoot continued as a normal long shoot with cataphylls and a terminal group of normal cladodes. The cataphylls at the base of this part indicate that it is formed a year later than the basal part with leaves. The shoot is terminated by a well- developed apical bud (Fig. 11e). Cross sections in the proximal region, where the oldest normal leaves are inserted, show three vascular bundles (Fig. 11b, c). The median one is concentric and is the stem bundle, supplying the distal, more or less long shoot-like part of the malformed cladode. The lateral two bundles are those of the two most basal leaves. In Fig. 11b one of the two lateral vascular bundles is already fully separated from the stem bundle, the other one is hit in the zone where it is inserted into the stem bundle and enters the leaf gap. The short-shoot axis is completely surrounded by parenchyma similar to that of the normal needle leaves. The cortical tissue that normally surrounds the stem bundle in long shoots is lacking completely. Each vascular bundle of the leaves is surrounded by its own bundle sheet and its xylem is oriented towards the stem bundle (Fig. 11a, b). The stem bundle has no bundle sheet and is much larger than the two leaf traces (Fig. 11a-d). The majority of the parenchymatic tissues resembles the spongy parenchyma of the leaves and the cladodes in having chlorophyll and large intercellular 
Fig. 7 Anomalous cladode with a leafy short-shoot continuing the basal cladode part. a Habit. b Cross section of a short shoot leaf; xylem $(X)$ on the adaxial and phloem $(P)$ on the abaxial side; mesophyll $(M)$ monomorphous; a single resin duct $(R S)$ on the abaxial side. c The vascular bundle is surrounded by a vascular bundle sheet $(V B S)$. d Stomata $(S)$ are between papillae $(P A P)$; the hypodermis has thickened cells $(H)$; a cuticula $(C)$ covers the epidermis (E)
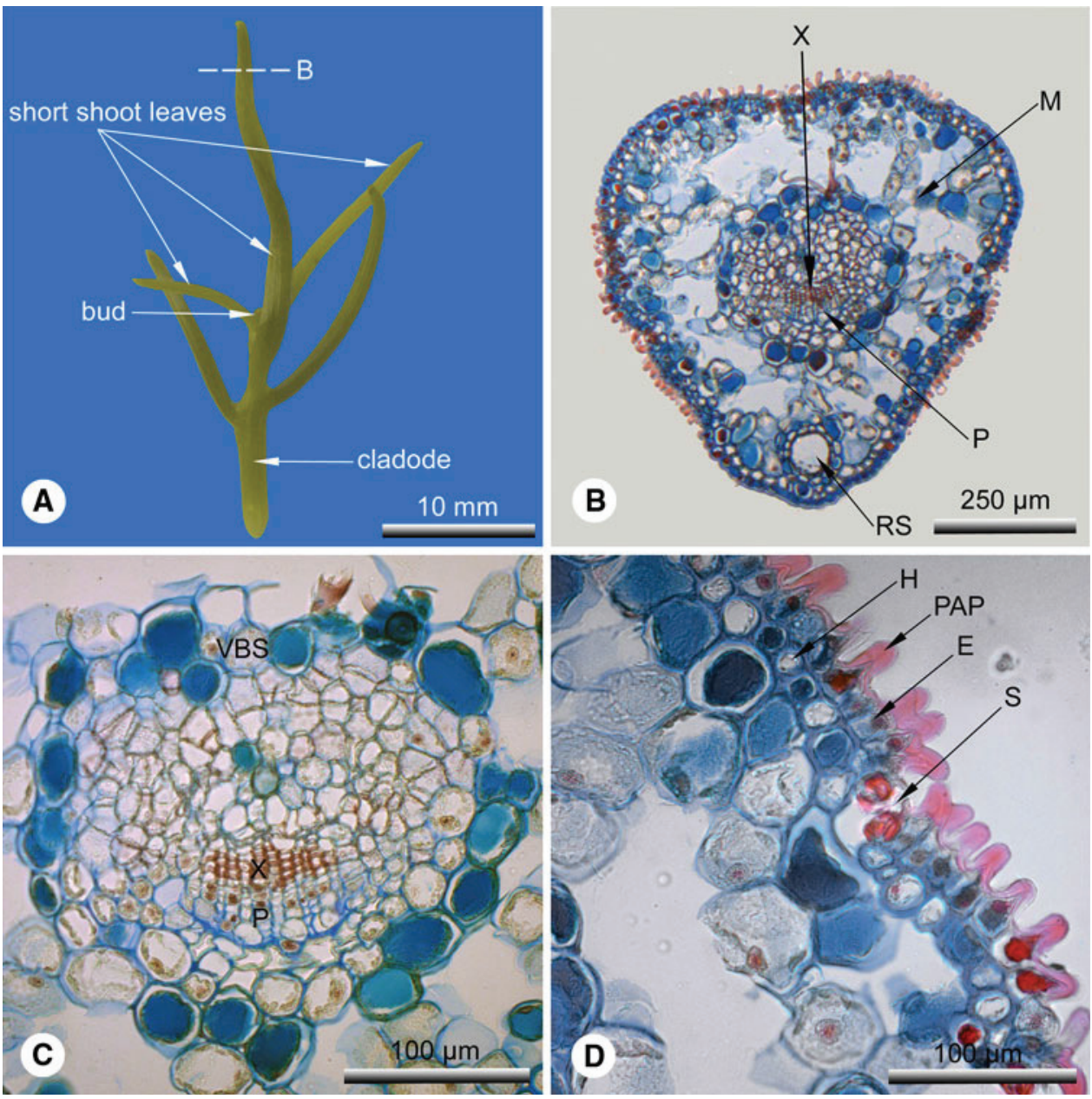

spaces. Only a small part on the lower side of the malformed cladode or branch shows the compact brownish tissue typical for the stem cortex (Fig. 11b, c). The stem bundle in this basal part shows a single, weakly developed annual growth ring (Fig. 11a).

\section{Anatomy of a typical long shoot}

The cross section in the terminal region of a 1-year-old long shoot axis, where the internodes are strongly reduced, shows several vascular bundles of the cladodes sectioned at different levels (Fig. 12). The more peripheral ones are inserted more basally and are therefore situated in the section more distal than the inner ones. Arrows $\mathrm{a}$ and $\mathrm{b}$ point to the two bundles of a cladode facing each other with the xylem side, but are still separated from each other by some parenchymatic cells. At arrow $\mathrm{c}$ both bundles of a cladode are fused to a concentric bundle with a slightly excentric phloem part. In $d$ the concentric bundle opens and xylem and phloem get contact with the respective stem tissues.

\section{Discussion}

Morphology and anatomy

The significance of teratologies is debated controversially. They can be roughly classified in to two groups. In one of them two developmental programs, which are usually processed simultaneously are exceptionally processed successively. In this case the teratology can help towards the understanding of the combined process. On the other hand, a teratology may reflect simultaneous processing of the developmental programs which are usually processed sequentially. It is unlikely that this may help towards the understanding of the processes which are not understood if they occur sequentially.

The malformations described here represent intermediates between the normal long shoots and normal short shoots or cladodes. They are not arranged arbitrarily but form a transition series from very similar to a normal long shoot to very similar to a normal cladode (Fig. 13). The malformed branches or cladodes thus represent a gradual 
Fig. 8 Typical cladode. a Distal part with two leaf tips. b Cross section; xylem $(X)$ on the lower and phloem $(P)$ on the upper side; mesophyll is subdivided in palisade $(P P)$ and in spongy parenchyma $(S P)$; resin ducts are arranged in the mesophyll on both sides of the cladode. c Vascular bundles surrounded by a vascular bundle sheet $(V B S)$. d In the furrow of the abaxial side, stomata $(S)$ are concentrated between papillae $(P A P)$; epidermis $(E)$ and hypodermis $(H)$ with thickened cells

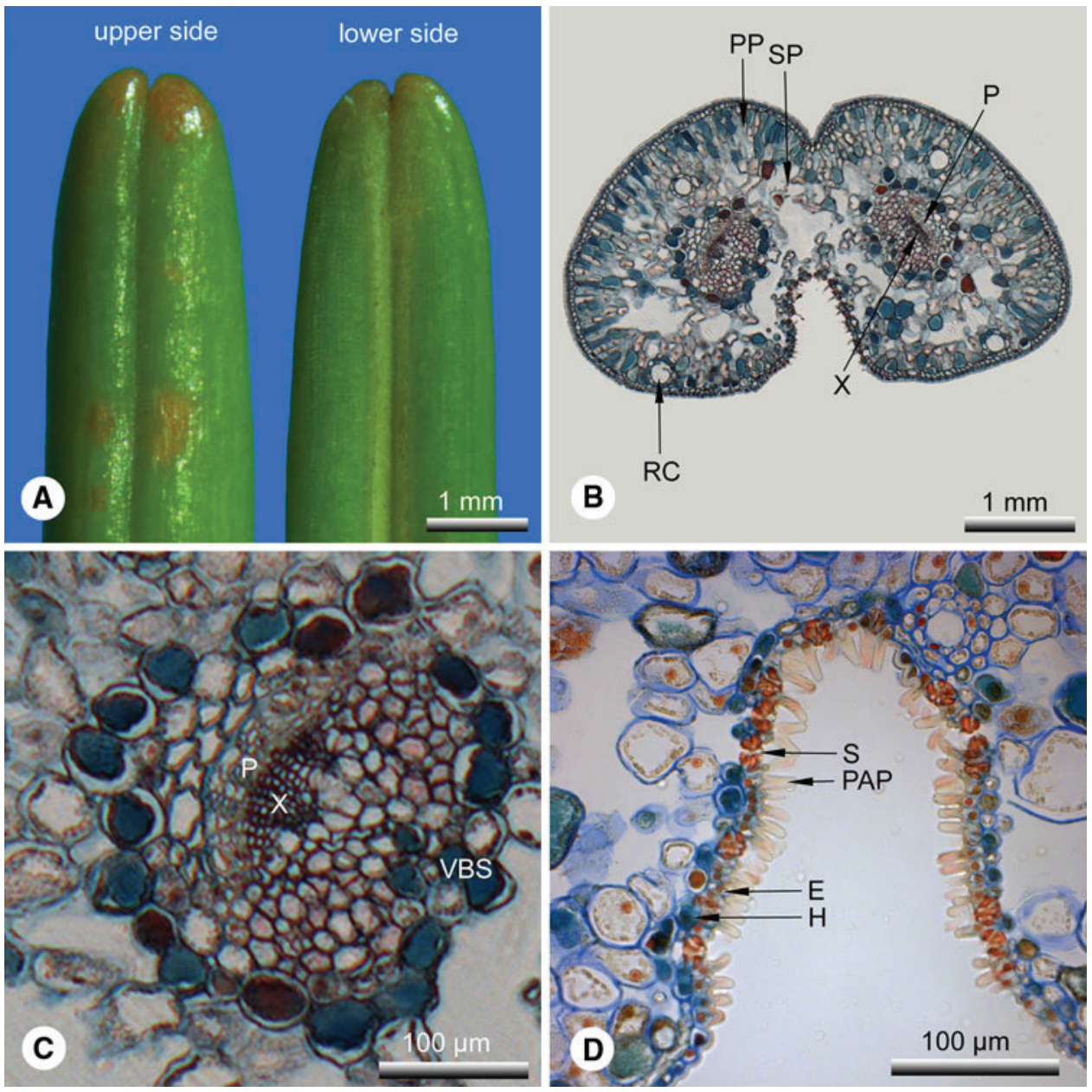

change of the bauplan where normally an abrupt change is found. This clearly indicates, that the observed abnormalities belong to the first type and may give meaningful insights in the morphology and phylogeny of Sciadopitys rather than representing just accidental artefacts.

So far the drawing of Carriére (1868) (Fig. 1) is the only report of such intermediates. As the drawing by Carriére show as only a part of a branch with the distal parts and proximal parts being cut, the relative position within the branching system cannot be detected. For the same reason, the formation sequence of the different types of lateral branches remains unclear.

Our observations clearly indicate that of the three possibilities to form a cladode of two leaves (Fig. 14) the version represented by Fig. 14b reflects the situation in Sciadopitys. This is best illustrated by the malformations with free distal ends (leaves) of the cladode (Fig. 9). In individual leaves the xylem of the only vascular bundle is always oriented to the adaxial side. This allows the identification of the side on which a presumed short-shoot apex should be positioned in the cladodes. Malformed cladodes with a rudiment of the shoot apex in fact show it always on the lower side as expected on the basis of xylem orientation. Cotyledons do not show a differentiation into spongy and palisade parenchyma and also lack a hypodermis, they are, however, hypostomatic and thus not fully aequifacial. Primary leaves (Fig. 4) as well as cladodes (Fig. 8) show the typical differentiation into spongy and palisade parenchyma and have a hypodermal layer similar to the epidermis in the transversal section. In primary leaves the stomata are distributed irregularly on the abaxial side. The cladodes have the stomata concentrated in the furrow on the abaxial side in a zone in which the epidermal cells are papillae (Fig. 8d). Leafy green long-shoot leaves (Fig. 6) as well as short shoot leaves (Fig. 7) on the malformed cladodes show no anatomical differentiation of the mesophyll, but have a hypodermal layer. Whereas the leafy long-shoot leaves have no epidermal papillae, the normal leaves on the malformed cladodes have papillae in three longitudinal zones and stomata arranged in these areas. One band of papillae is developed on the adaxial side just above the xylem, the other two turn to the lower lateral sides of the nearly triangular leaf (Fig. 7b).

In the cladode with three bundles (Fig. 10) they form a semi-circle turning all the xylem to the furrow on the lower side, where an apex would be expected but is not present in 
Fig. 9 Cladodes with free ends. a Cladode only connated to half of its length. b Cross section of the connated part; mesophyll is differentiated in palisade $(P P)$ and spongy parenchyma $(S P)$; xylem is arranged to the abaxial and phloem to the adaxial side; resin ducts are on both sides of the cladode. c Each vascular bundle has its own vascular bundle sheet. d Under the epidermis $(E)$ lies a hypodermis $(H)$; stomata $(S)$ are concentrated between papillae $(P A P)$. e Cross section of the distal free ends; xylem and phloem are arranged as in the connected part. f Stomata occur only in the furrow of the connected part
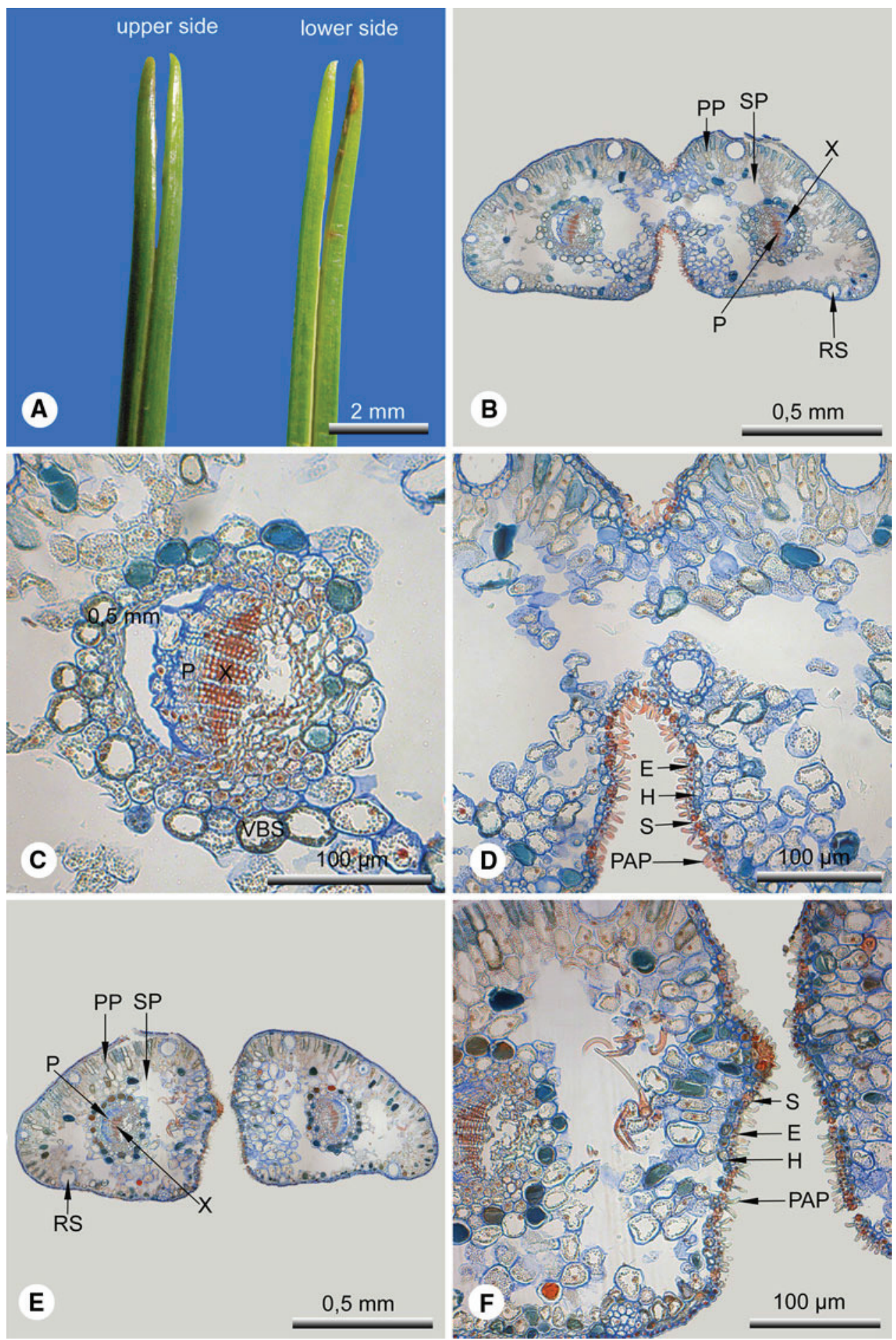

this sample. In one malformed cladode two lateral vascular bundles and the stem bundle with two leaf gaps can be seen (Fig. 11). The two leaf bundles enter the leaf gaps and are inserted into the stem bundle. If the central stem bundle in the schematic representation in Fig. $15 \mathrm{~b}$ is omitted, the result is what is usually found in a normal cladode (Fig. 8b). This interpretation fits with the observation, that in normal cladodes the two foliar bundles fuse into a concentric bundle that enters the main axis (Fig. 12). As a result, the insertion of the cladode vasculature into the stem resembles the insertion of a lateral axis. The rudimentary long-shoot scaly leaves have no (Fig. 5) or rarely only a reduced vascular bundle that is not attached to the stem system but ends blindly on both the sides. As a 
Fig. 10 Morphology and anatomy of a cladode with three vascular bundles. a Distal region with three leaf tips. b Cross section, xylem $(X)$ is arranged to the lower and phloem $(P)$ to the upper side; mesophyll is subdivided in palisade $(P P)$ and in spongy parenchyma $(S P)$; resin ducts are arranged to the upper side. c Each vascular bundle is surrounded by a vascular bundle sheet $(V B S)$. d On the lower side stomata $(S)$ occur between papillae $(P A P) ; E$ epidermis, $H$ hypodermis

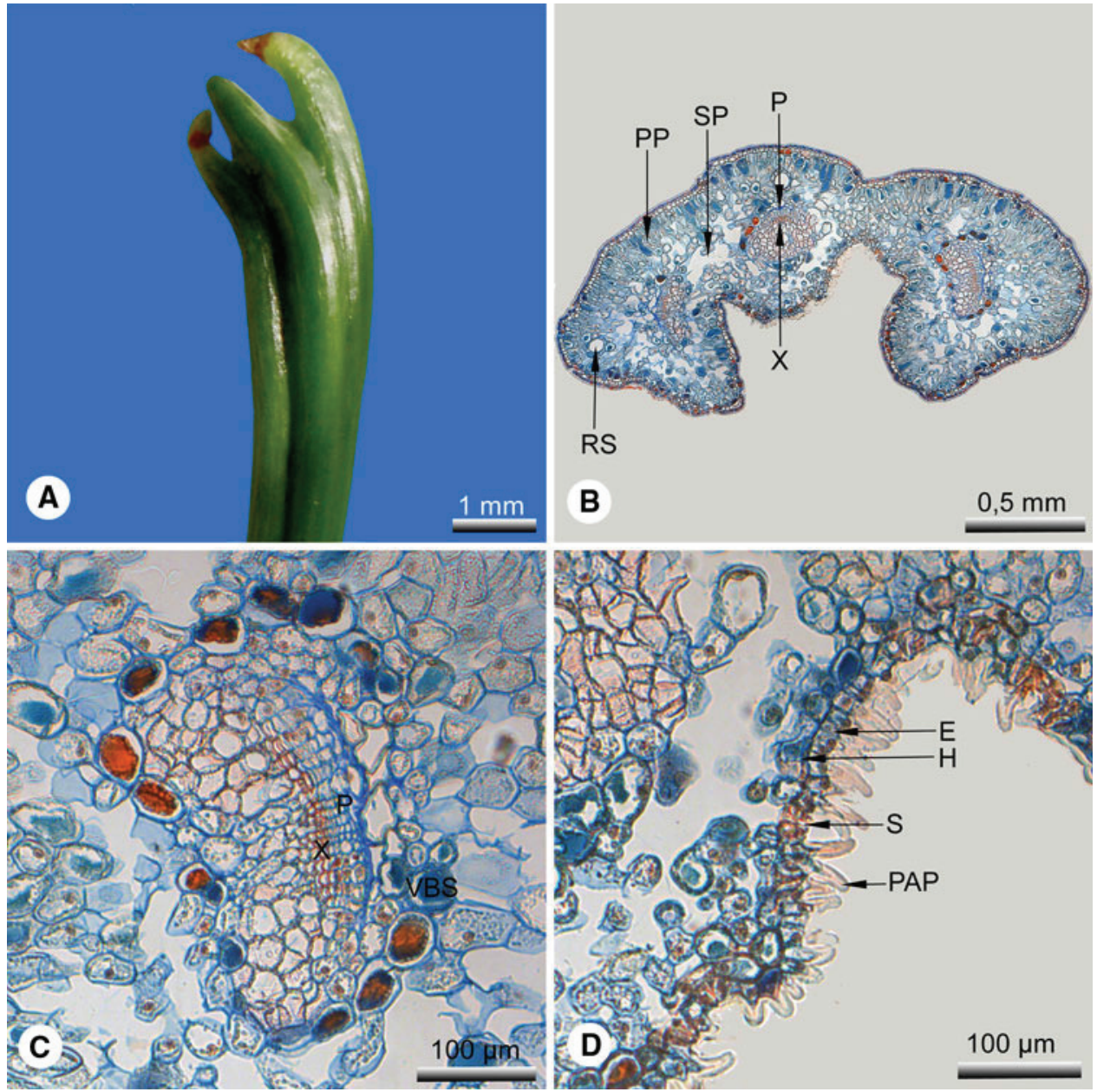

consequence, there is no leaf gap to insert the leaf bundles of the cladode into the stem. The concentric bundle in the insertion zone of the cladode has to open again to get inserted into the stem as described by Hille (2008).

Although the orientation of xylem and phloem is informative and gives clear insights in to the developmental and evolutionary patterns, the formation of palisade parenchyma does not. Palisade parenchyma is always developed on the side, which is best exposed to the sun, regardless of whether it is the original adaxial or abaxial side of the leaf. This kind of functional adaption of the anatomy is also known from several other gymnosperms. The lateral scaly leaves of Cupressaceae (e.g., Thuja, Platycladus) develop palisade parenchyma on the side exposed to the sun (the former abaxial side of one half of the leaf); palisade parenchyma is lacking on the entire adaxial side and the abaxial half of the leaf of the lower side of the branch. The scale leaf on the upper side of the branch develops a dorsal palisade parenchyma, the leaf on the lower side does not develop any palisade parenchyma (Tetzlaf 2004; Hille 2008). Here the same functional transformation takes place, as it can be found in S. verticillata. In this case functional constructions overrule the basic bauplan.

The position of the resin ducts appears to be of limited relevance. In cotyledons and primary leaves most resin ducts are close to the abaxial surface. This seems to fit with the fact that in normal cladodes most resin ducts are close to its upper surface, which consists basically of the abaxial surfaces of the two individual leaves, which make it up. The leafy green long-shoot leaves, however, have the most resin ducts on the adaxial side. The position and distribution of the resin ducts seems therefore to be somewhat ambiguous.

It is now also clear, why our earlier experiments in which we tried to force Sciadopitys plants to produce the abnormities described by Carrière by destroying all vegetative apices on a branch failed. The abnormities described by Carrière and here originate in the primary morphogenesis and cannot be induced after primary morphogenesis is finished. A study of the primary morphogenesis was, however, not possible, as the abnormalities are too rarely 
Fig. 11 Cross sections a of 2-year-old malformed shoot of Sciadopitys verticillata with a prominent shoot axis from proximal to distal. a Distal part with two separate needle leaves. b Three vascular bundles $(V B)$; the central vascular bundle of the shoot is concentric; the two lateral ones of the needle leaves, are each surrounded by an own bundle sheet. $\mathbf{c}$ The vascular bundle of leaf 1 is full developed, the vascular bundle of leaf 2 just draws out of the shoot axis. d In the proximal part of the shoot only the concentric shoot bundle can be found e Entire 2-year-old anomalous short shoot with a prominent shoot axis; lines indicate transversal sections, $A-D$ hatched
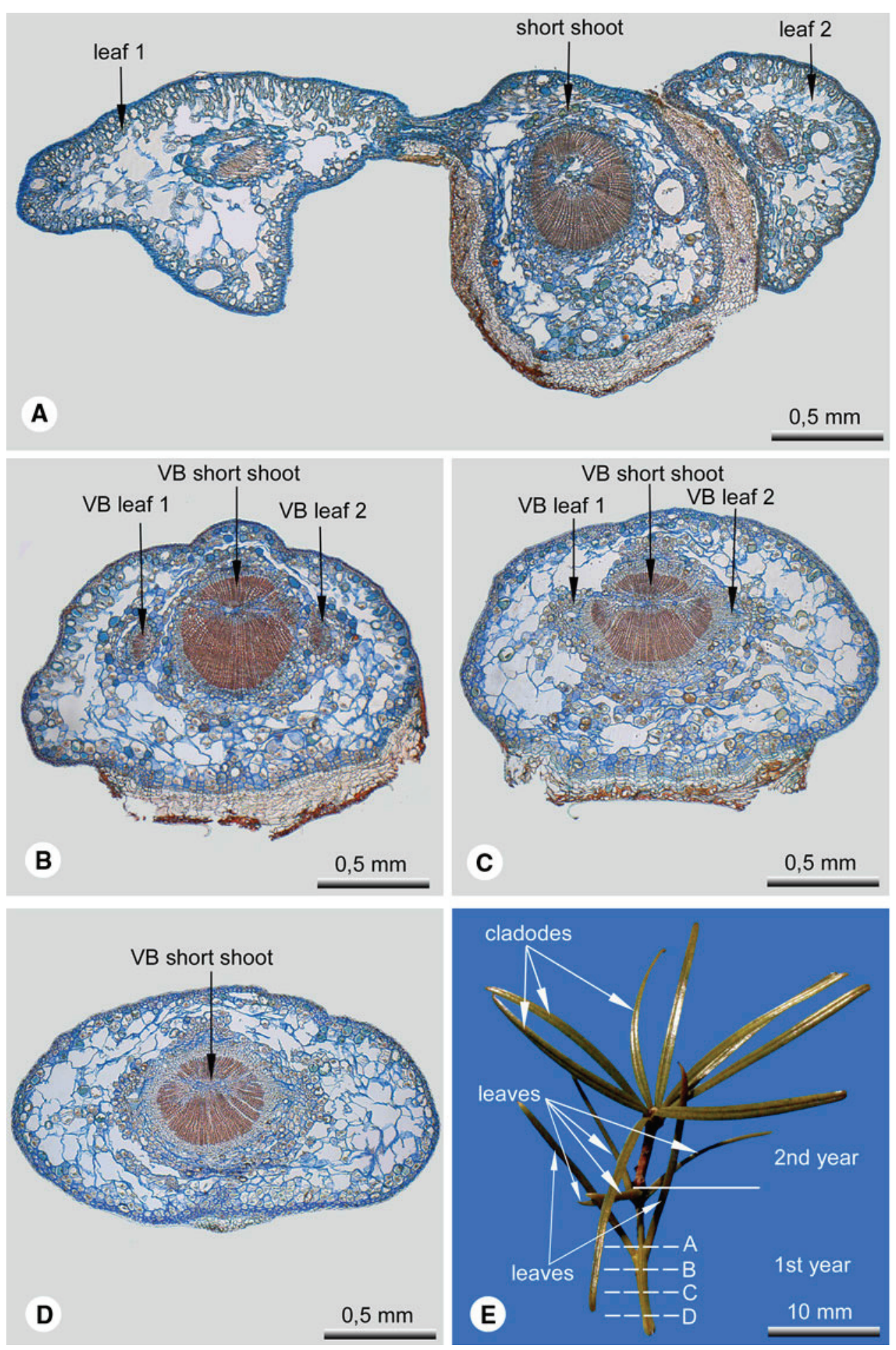

found in the different developmental stages in the young buds. As different types of malformations occur, it is furthermore never clear to which type an observed early stage would have led to its further development. Our insights in to the developmental aspects are thus exclusively the conclusions from an analysis of mature malformations of a related type.
Phylogenetical and evolutionary implications

In the past Sciadopitys was widely distributed in the Northern Hemisphere (Studt 1927). It is quite common that representatives of old gymnosperm taxa are today monotypic and restricted to very small disjunct areas (Jagels and Equiza 2005; LePage et al. 2005; Meyer 2005; Momohara 


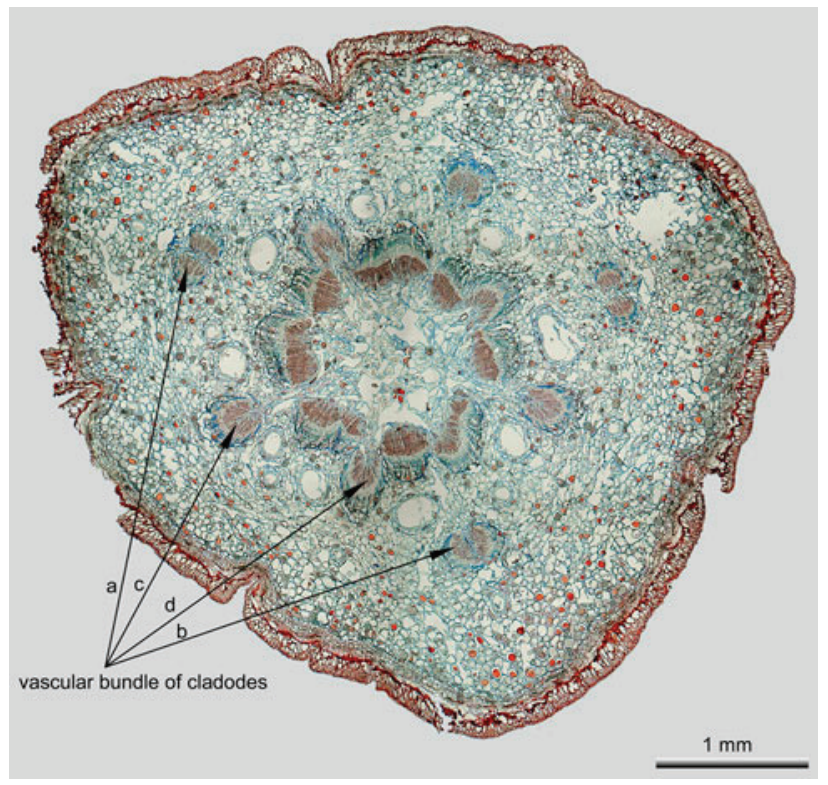

Fig. 12 Cross section of a 1-year-old long shoot axis of Sciadopitys verticillata; the two vascular bundles of a normal cladodes fuse into a concentric bundle which then enters the main axis (for high-resolution zoom in image see http://www.ruhr-uni-bochum.de/boga/spezbot/ scientificillustrations.htm)

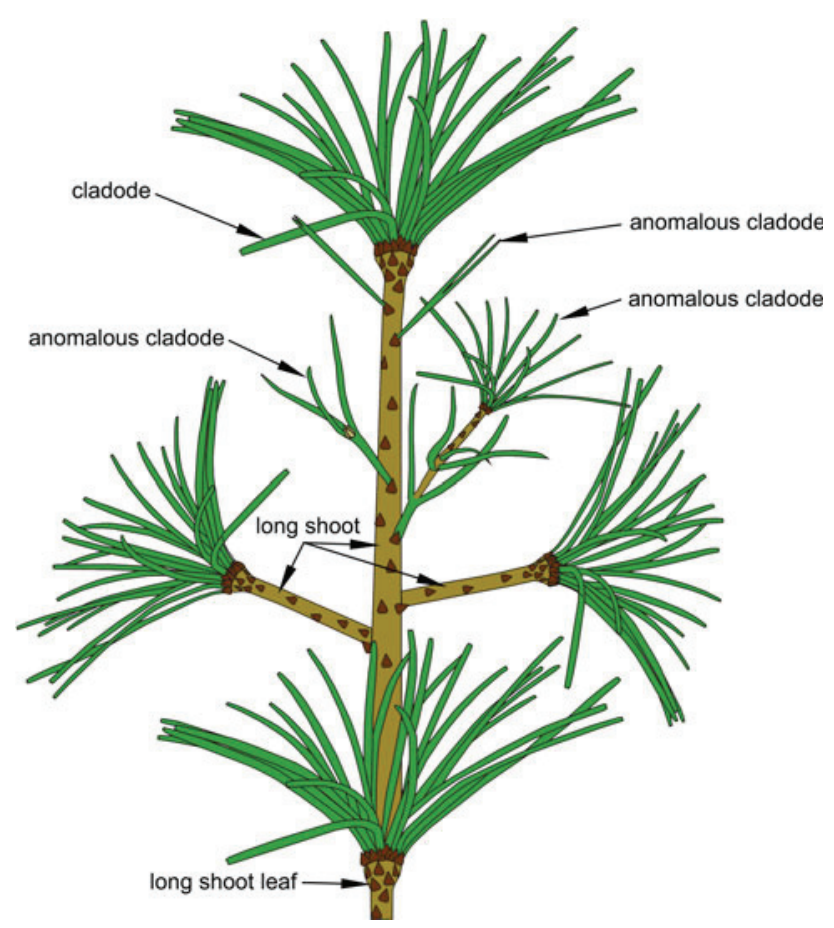

Fig. 13 Position of anomalous cladodes in the branching system

2005; Richter and LePage 2005; Parakash and Kumar 2004; Royer et al. 2003). Well-known representatives of such relict taxa are Metasequoia, Sequoia, Sequoiadendron and Glyptostrobus. It is, however, unknown whether these species were evergreen or deciduous in previous times. Before angiosperms had evolved, many of the habitats covered today by deciduous green forests might have been covered with deciduous green gymnosperms. It seems that evolving angiosperm trees have competed out deciduous gymnosperms and forced them to shift to an evergreen condition (Dörken 2008; Dörken and Stützel 2009). At least for most Cupressaceae it could be shown (Dörken 2008) that shoot abscission structures, common in deciduous Cupressaceae like Taxodium, Glyptostrobus and Metasequoia, occur in all Cupressaceae mostly, however, without (longer?) playing anymore a role in their ecology. Following this idea, the ancestor of Sciadopitys might have been a deciduous plant with long-shoot/short-shoot differentiation. Changing or returning to an evergreen condition, the short shoots might have been reduced and transformed into cladodes. It might be thus possible, that the ancestor of Sciadopitys, with deciduous short shoots cannot be recognized in the fossil record as closely related to this taxon. Perhaps the structure of vascular scleriids might help to solve this problem.

Evergreen cladodes can make long-shoot leaves superfluous, which explains why they are reduced to minute scales. Despite growing best in relatively humid places today, Sciadopitys shows a series of xeromorphic adaptations such as a continuous hypodermal layer without intercellular spaces, a very prominent cuticle and stomata sunken in a furrow in which the epidermal cells form papillae or unicellular hairs (Fig. 8b, d). The discovery of "leafy" long shoots and cladodes made up of three leaves can be regarded as atavism and may support the idea of a deciduous ancestry for Sciadopitys.

Long-shoot/short-shoot differentiation is typical for all deciduous angiosperm trees and has a clear functional meaning. In evergreen gymnosperms long-shoot and shortshoot differentiation is best understood as a relic of a previously deciduous condition. A reversal to an evergreen condition may lead to a reduction of the short-shoots and the long-shoot leaves as it can be seen in Pinus with the extremely reduced Pinus monophylla having only a single green leaf per short shoot. Only on some short shoots two needle leaves can be found (Gottfried and Negron 2004; Dörken 2008).

Reductions of long-shoot needle leaves can also be found in other gymnosperm groups, e.g., the Pinaceae. In the first years young individuals, e.g. of Pinus, show only long shoots with typically shaped "leafy" needle leaves (Fig. 16a). But with the beginning of the long-shoot/shortshoot differentiation the long-shoot needle leaves are strongly reduced (Fig. 16b), so that they finally become scaly leaves (Fig. 16c), which no longer take part in the photosynthesis. The shoot differentiation in Pinus is thus a functional analogy to what we find in Sciadopitys and may 
Fig. 14 Hypothesis for the formation of Sciadopitys cladodes. a Two leaves fused with the entire ventral surface, remains of the apex on the top of the cladode. b Two leaves fused with the margins facing the main axis, remains of the apex on the lower side if present. c Two leaves fused with the margins facing the pherophyll (sublending leaf) main axis on the upper side if present (dark grey individual leaves; black fusion zone; bright grey fusion product (cladode); $A P$ apex)

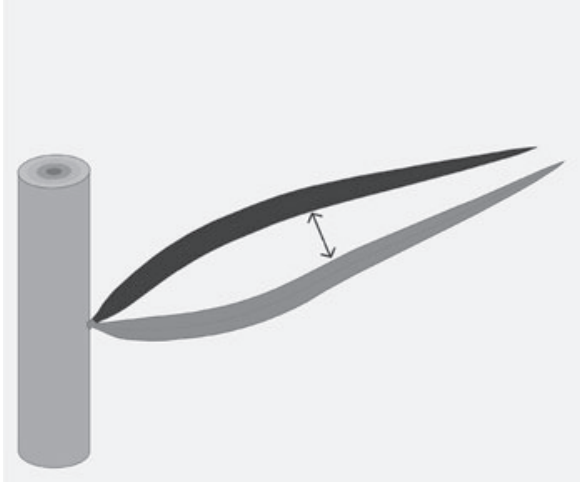

A
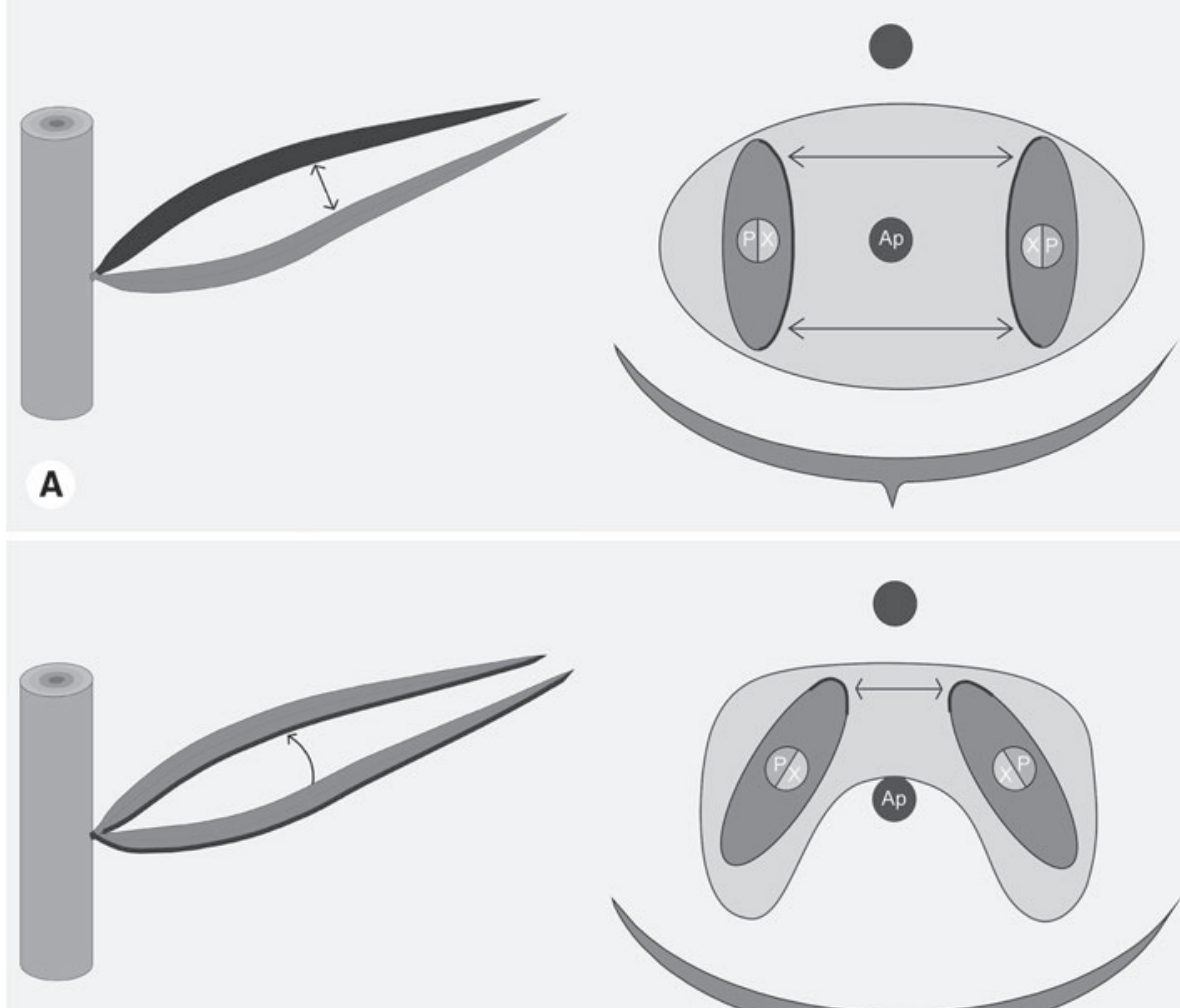

B
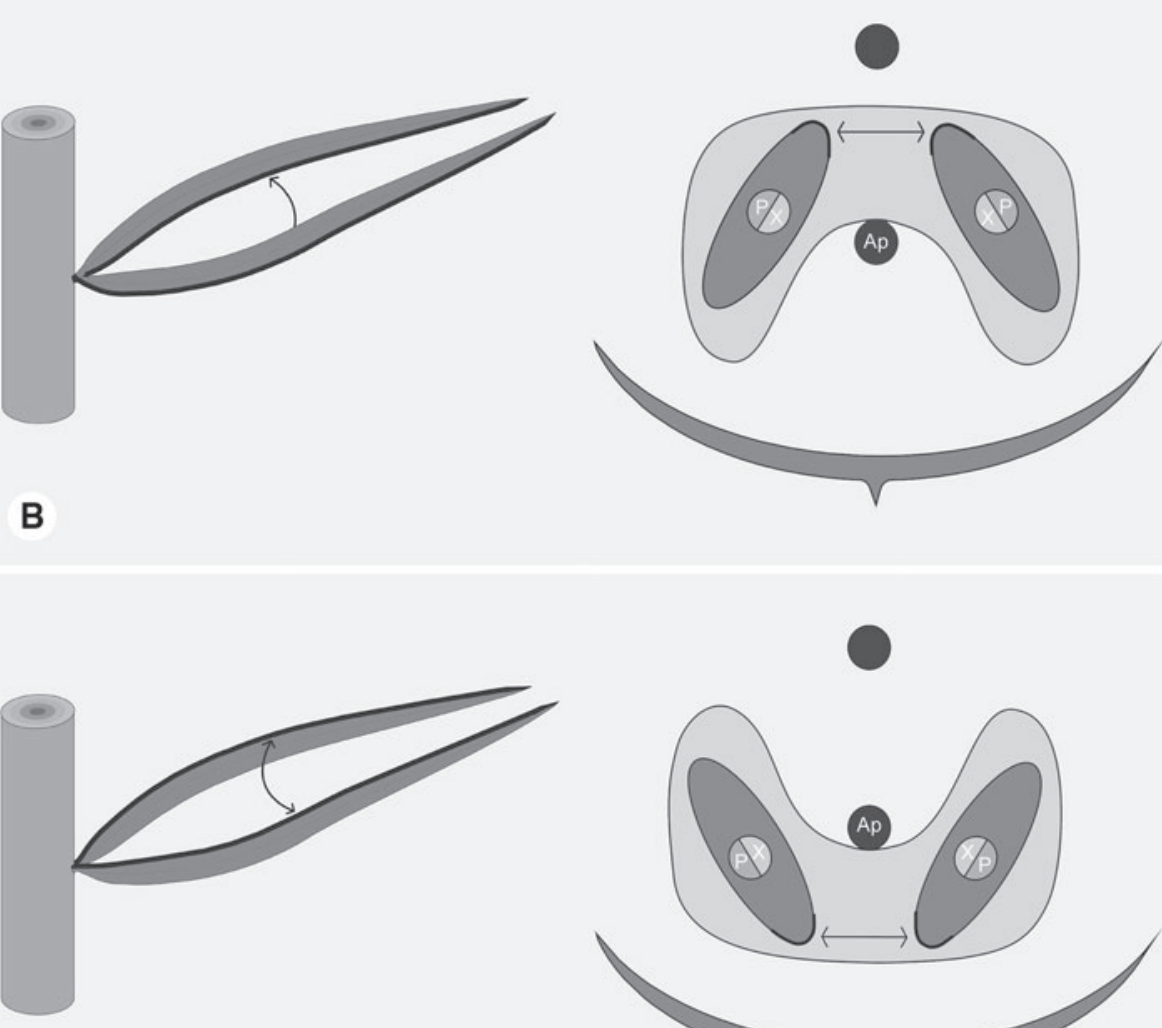

C also be an analogy with respect to the evolutionary constants.

Via the formation of cladodes, evergreen species can return to a morphology, which is functionally identical to the situation in normal evergreen species lacking a shoot differentiation. In Sciadopitys it is still possible to detect that the "double-needles" are cladodes. The long-shoot scales are, however, very reduced and without vascularisations or only short vascular strands that have lost their function. A further reduction, e.g. of the scaly long shoot leaves, would lead to a situation, in which the cladode can no longer be distinguished from the normal leaves on the basis of morphological features. It seems therefore possible that "the gymnosperm leaf" is not a homologous structure in all gymnosperms.

\section{Conclusions}

The described malformations of cladodes in Sciadopitys are probably the second record of such structures. Their anatomy has been studied here for the first time. The 


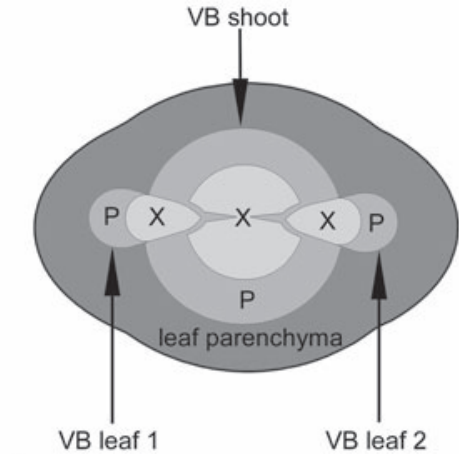

A

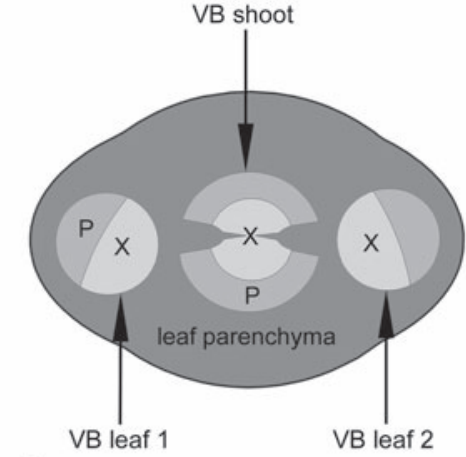

B

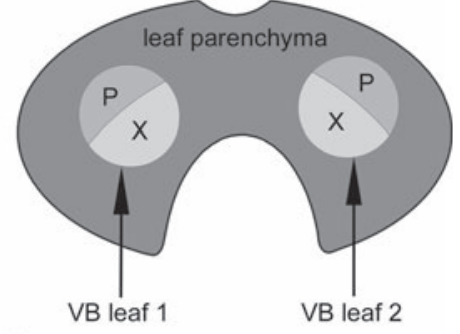

C
Fig. 15 Transitions to a Sciadopitys-cladode. a, b From one abnormalous short shoot. c Typical cladode; the lateral bundles in $\mathbf{b}$ are inserted in the stem bundle in $\mathbf{a}$; reduction of the stem bundle leads to the typical cladode anatomy in $\mathbf{c}$, these two bundles also form a concentric bundle before entering the main axis; $V B$ vascular bundle, $p$ phloem, $x$ xylem
Fig. 16 Pinus monophylla; a 3 -year-old seedling without any shoot differentiation; only a long shoot and long-shoot leaves are developed. b With the beginning of the shoot differentiation long-shoot leaves get strongly reduced. c When the shoot differentiation is fully developed, long shoot leaves are, as it is the case for Sciadopitys, only rudimentary, scaly bracts which do not take part in the photosynthesis
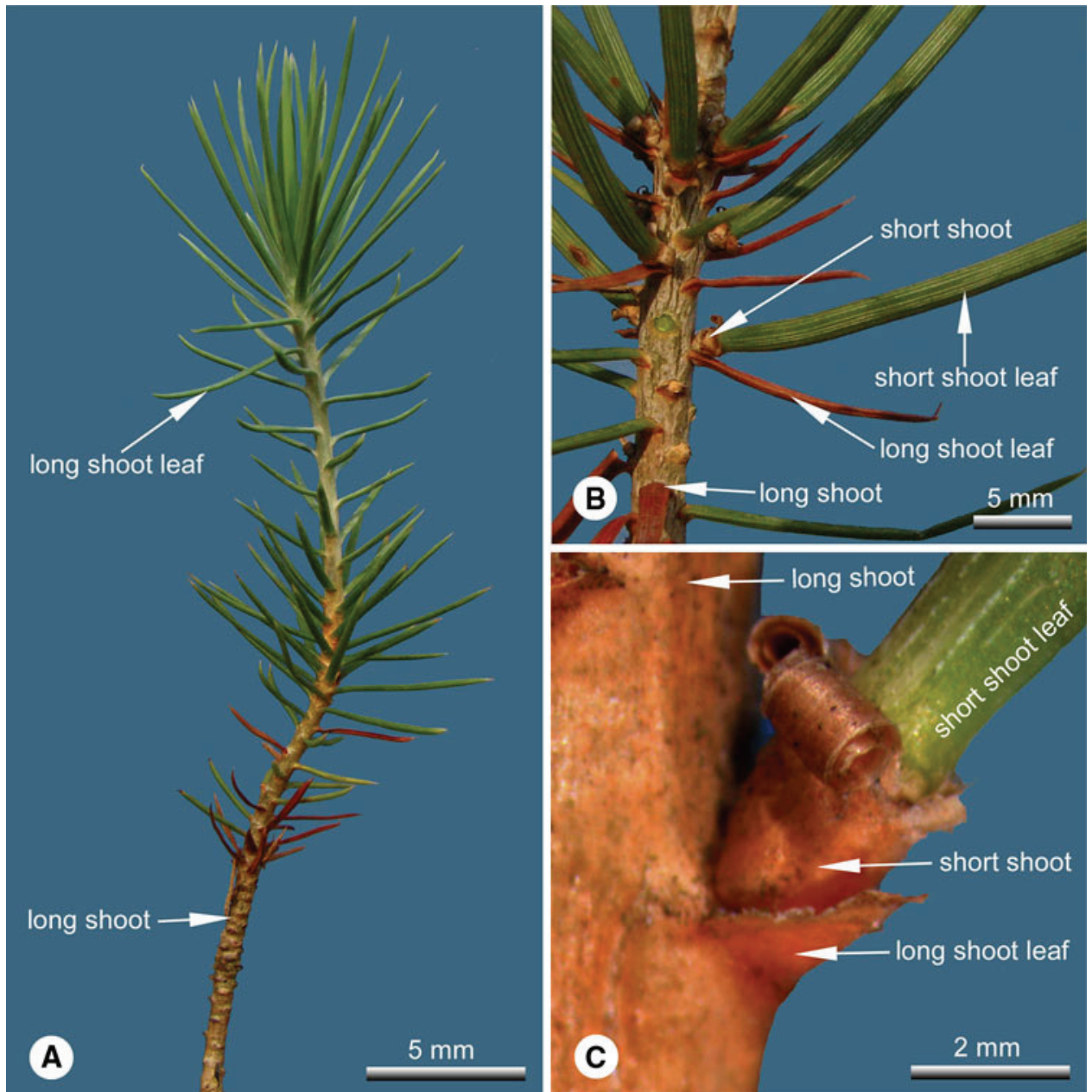

different malformations can be regarded as the intermediary steps from a normal short shoot to an evergreen cladode. The data enable to answer all open questions with regard to the nature of the cladode in Sciadopitys. Only few additional reductions would be needed to transform the Sciadopitys cladode into a structure that can no longer be distinguished from a normal leaf. Therefore, not all leaves of extant gymnosperm taxa are necessarily homologous. 
Acknowledgments We gratefully acknowledge the help by the two anonymous reviewers. Their comments helped us to express our ideas in a clear and more straight forward manner. Moreover, they gave suggestions for significant linguistic improvement.

\section{References}

Carrière EA (1868) Annomalies preséntées par de feullies de Sciadopitys. Rev Hort 40:150-151

Dickson A (1866) On the phylloid shoots of Sciadopitys verticillata Sieb. \& Zucc. J Bot 4:224-225

Dörken VM (2008) Saisonalität und Langtrieb-/Kurztrieb-Differenzierung in Gymnospermen, ursprünglich oder abgeleitet? $\mathrm{PhD}$ thesis, Ruhr-University Bochum

Dörken VM, Stützel T (2009) The adaptive value of shoot differentiation in deciduous trees and its evolutionary relevance. Bol Soc Argen Bot 44(3-4):421-439

Engelmann G (1868) Ueber die Charactere der Abietineen-Genera. Bot Z 30:486

Gerlach D (1984) Botanische Mikrotomtechnik, eine Einführung, 2nd edn. Thieme, Stuttgart

Gottfried GJ, Negron JF (2004) Pinus monophylla. In: Schütt P, Weisgerber HJ, Schuck UM, Lang B, Stimm RoloffA (eds) Lexikon der Nadelbäume, Sonderausgabe 2004. Nikol, Hamburg

Hille N (2002) Vergleichende Studien zur Anatomie und Histogenese von Gymnospermenblättern. Diploma, Ruhr-University Bochum Bochum

Hille N (2008) Morphologische und entwicklungsgenetische Studien zur Blattent-wicklung und Blattevolution bei Gymnospermen am Beispiel Sciadopitys verticillata Siebold \& Zucc. PhD thesis, Ruhr-University Bochum

Jagels R, Equiza MA (2005) Competitive advantages of Metasequoia in warm latitudes. In: LePage BA, Williams CJ, Yang H (eds) The geobiology and ecology of Metasequoia. Springer, Heidelberg, pp 335-349

LePage BA, Yang H, Matsumoto M (2005) The evolution and biogeographic history of Metasequoia. In: LePage BA, Williams
CJ, Yang H (eds) The geobiology and ecology of Metasequoia. Springer, Heidelberg, pp 3-114

Meyer HW (2005) Metasequoia in the oligocene Bridge Creek Flora of Western North America: ecological implications and the history of research. In: LePage BA, Williams CJ, Yang H (eds) The geobiology and ecology of Metasequoia. Springer, Heidelberg, pp 159-186

Mohl H (1871a) Morphologische Betrachtung der Blätter von Sciadopitys. Bot Z 1:1-14

Mohl H (1871b) Morphologische Betrachtung der Blätter von Sciadopitys. Bot Z 2:17-23

Momohara A (2005) Palaeoecology and history of Metasequoia in Japan, with reference to its extinction and survival in East Japan. In: LePage BA, Williams CJ, Yang $\mathrm{H}$ (eds) The geobiology and ecology of Metasequoia. Springer, Heidelberg, pp 115-136

Parakash N, Kumar M (2004) Occurrence of Ginkgo Linn. in early cretaceous deposits of South Rewa Basin, Madhya Pradesh. Curr Sci 87(11):1512-1515

Richter SL, LePage B (2005) A high-resolution palynological analysis, Axel Heiberg Island, Canadian High Arctic. In: LePage BA, Williams CJ, Yang H (eds) The geobiology and ecology of Metasequoia. Springer, Heidelberg, pp 137-158

Roth I (1962) Histogenese und morphologische Deutung der Doppelnadeln von Sciadopitys. Flora 152:1-23

Royer DL, Hickey LJ, Wing SL (2003) Ecological conservatism in the "living fossil" Ginkgo. Paleobiology 29(1):84-104

Schneider W (1913) Vergleichend-morphologische Untersuchung über die Kurztriebe einiger Arten von Pinus. Flora 105:30-40

Strasburger E (1872) Die Coniferen und Gnetaceen. A Abel Leipzig 49:382-390

Studt W (1927) Die heutige und frühere Verbreitung der Koniferen und die Geschichte ihrer Arealgestaltung. Mitteilungen aus dem Institut für allgemeine Botanik Hamburg 6(3):169-307

Tetzlaf M (2004) Die Anatomie des Gymnospermenblattes unter funktionellen und evolutiven Gesichtspunkten. Diploma, RuhrUniversity Bochum Bochum

Troll W (1937) Vergleichende Morphologie der höheren Pflanzen, Teil 1. Borntraeger, Berlin, pp 551-555 